\title{
Ultrasonic Piezoelectric Nebulization of Propoxur for the Determination by Corona Discharge Ionization Ion Mobility Spectrometry
}

\author{
Alireza TABIBI and Mohammad T. JAFARI ${ }^{\dagger}$ \\ Department of Chemistry, Isfahan University of Technology, Isfahan 84156-83111, Iran
}

\begin{abstract}
Propoxur insecticide as a thermally unstable compound (decomposed at its boiling point) could not be analyzed by traditional sample introduction systems based on the thermal desorption. In this study, an ultrasonic piezoelectric nebulizing injection port was applied for evaporating this compound prior to its determination by corona discharge ionization ion mobility spectrometry (CD-IMS). The target analyte was extracted from different water samples by using the extraction method of dispersive liquid-liquid microextraction. Methanol and trichloromethane were utilized as the disperser and extraction solvents, respectively. The effective variables included the volume of the disperser and the extraction solvents, the $\mathrm{pH}$, and the centrifugation time were studied by a Fractional Factorial Design to identify the important parameter(s) and their interaction. To that end, a Central Composite Design was performed to achieve optimum levels of each effective parameter. The results showed that the optimum conditions were $78 \mu \mathrm{L}$ of the extraction solvent, and $1.2 \mathrm{~mL}$ for the disperser solvent; centrifugation time was $1 \mathrm{~min}$ at $1010 \mathrm{~g}$, and finally $\mathrm{pH} 7$. A detection limit of $2.1 \mu \mathrm{g} \mathrm{L}^{-1}$, a linear range of $2.5-80 \mu \mathrm{g} \mathrm{L}^{-1}$, and a relative standard deviation of $7 \%$ were obtained. Different water samples were analyzed by the proposed technique, and the propoxur amounts were successfully determined. The obtained results revealed satisfactory relative recovery values of between 91 and $105 \%$.
\end{abstract}

Keywords Propoxur, thermally unstable compounds, dispersive liquid-liquid microextraction, ultrasonic piezoelectric nebulization, ion mobility spectrometry

(Received July 10, 2019; Accepted September 17, 2019; Advance Publication Released Online by J-STAGE September 27, 2019)

\section{Introduction}

Propoxur is an $N$-methylcarbamate insecticide with an IUPAC name of 2-isopropoxyphenyl methylcarbamate. Carbamate insecticides are very effective for pest eradication, and cause an irreversible inhibition of the acetylcholinesterase enzyme (AChE) which leads to interruption the nervous system. ${ }^{1}$ Propoxur is suitable for killing most insect pests, like fleas, household pests, and flies, and it used for both agriculture and public health properties. ${ }^{2}$ This compound is soluble in water (1860 $\mathrm{mg} \mathrm{L}^{-1}$ at $30^{\circ} \mathrm{C}$ ), and polar organic solvents, but has only little solubility in non-polar organic solvents. ${ }^{3}$ Propoxur has medium or low stability and also low affinity in the soil matrix; ${ }^{4}$ thus it can cause serious groundwater pollution. ${ }^{5}$ As reported by the World Health Organization, the maximum residue limit of propoxur is estimated to be $3 \mathrm{mg} \mathrm{kg}^{-1}$ for vegetables, and lower than $0.05 \mathrm{mg} \mathrm{kg}^{-1}$ for other foods. ${ }^{6}$

On the other hand, most $N$-carbamates are thermally unstable and are usually analyzed by spectrophotometric methods ${ }^{7-9}$ and high-performance liquid chromatography (HPLC). ${ }^{10-12}$ Gas chromatography (GC) as one of the popular analytical instruments may also be used for analyzing these compounds; however, with some modification in the sample preparation or instrumentation. In fact, using a common GC with hot injectors

$\dagger$ To whom correspondence should be addressed.

E-mail: jafari@iut.ac.ir leads to destruction of the chemical structures of these compounds. In many cases, carbamate compounds have been determined by GC after derivatization of the analyte. ${ }^{13,14}$ Some other methods, including programmed temperature vaporizer devices, ${ }^{15}$ short column $\mathrm{GC}^{16}$ and low-pressure GC, ${ }^{17}$ have been developed to make the possibility of GC usage; with the minimum decomposition of $\mathrm{N}$-carbamate. For example, Song and McNair reported a method for analyzing carbamates by using a fast GC with cold on-column injection. ${ }^{18}$ However, according to their results, at the heating rate of more than $50^{\circ} \mathrm{C} \mathrm{min}{ }^{-1}$, the thermal decomposition of propoxur would be significant. Therefore, while considering this problem, many researchers have been encouraged to use LC or HPLC, for the determination of propoxur; however, this method also suffers from expensive and harmful chemical solvents, in addition to a long run-time required for analysis. ${ }^{19}$

Ion mobility spectrometry (IMS), introduced by Karasek in $1970,{ }^{20}$ has been used as an analytical technique to separate and identify chemical compounds in the gaseous environment and atmospheric pressure. The operation principle of the technique is based on the ionic mobility of species in an electric field, depending on the mass, charge, and shape of ions. The sample molecules need to be ionized, usually through techniques involving radioactive sources, ${ }^{21}$ corona discharge, ${ }^{22}$ and electrospray ionization source. ${ }^{23,24}$ The originated ions are separated under the influence of an electric field and drift gas flow, in the opposite direction of ions migration. When ions arrive at the collector, positioned at the end of the drift tube, 
the corresponding ion peak(s) appear in the ion mobility spectrum..$^{25}$ IMS has a wide range of applications in the analysis of explosives, medical drugs, pesticides, and air pollutants, due to its high speed, ruggedness, sensitivity, and ease of maintenances. ${ }^{26,27}$

The thermal desorption injection port is commonly used to make a gas-phase sample, prior to analysis by IMS equipped with corona discharge or ${ }^{63} \mathrm{Ni}$ ionization sources. However, this sample introduction system cannot be used for thermally unstable materials due to decomposition of their molecules. Very recently, an ultra-sonic piezoelectric injection port has been introduced for analyzing thermally unstable compounds by a stand-alone IMS equipped to a corona discharge ionization source (CD-IMS). ${ }^{28}$ This injection port can evaporate the sample based on an ultrasonic piezoelectric device, oscillating with RF frequency to transfer the energy to a liquid and form fine droplets.

In this work, the propoxur insecticide was successfully identified and measured by corona discharge ion mobility spectrometry equipped with an ultrasonic injection port (US-CD-IMS). In order to preconcentrate and extract the propoxur from aqueous solution, the dispersive liquid-liquid microextraction (DLLME) method was used with an extraction solvent heavier than water. Some parameters affecting the extraction were optimized using the Design-of-Experiment (DOE) method. Some real samples of agricultural wastewater, underground water, and wastewater of aviculture were analyzed for an applicability survey.

\section{Experimental}

\section{Reagents and chemicals}

Acetone, dichloromethane, acetonitrile, trichloromethane, and tetrachloromethane obtained from Merck (Darmstadt, Germany) and methanol (HPLC grade) were purchased from Dae-Jung (Shiheung, Korea). The propoxur pesticide was prepared from Samgol Company (Tehran, Iran) and its stock solution was prepared in methanol with a concentration of $1000 \mathrm{mg} \mathrm{L}^{-1}$. Working solutions were prepared, daily, by diluting the stock solution. All of the solutions were stored at $4{ }^{\circ} \mathrm{C}$ in a refrigerator.

\section{Apparatus}

The instrument, ion mobility spectrometer, with corona discharge ionization source were designed and constructed by Teif Azmon Espadana Company (Isfahan, Iran). The instrument was equipped with an ultrasonic piezoelectric nebulizer as sample introduction system, described previously. ${ }^{28-30}$ Briefly, the IMS instrument comprises the IMS cell counting the corona discharge ionization system, a pulse generator, two high-voltage power supplies, an analog-to-digital converter, and a computer. The sample introduction system contained a piezoelectric element in a cylindrical glass which was closed by a piece of PTFE. Samples were injected through a septum by a $25-\mu \mathrm{L}$ syringe. By applying an electric voltage ( $40 \mathrm{~V}$ and $2.5 \mathrm{MHz})$ to the piezoelectric element, the sample solution was nebulized and carried into the reaction region, by the nitrogen gas flow. The working conditions of the CD-IMS are shown in Table S1, in Supporting Information. The ion mobility spectrum obtained after injecting the standard propoxur compared to the background of the instrument is shown in the Supporting Information, Fig. S1. This figure shows only one ion peak (drift time of $9.92 \mathrm{~ms}$ ), which originated from the analyte.

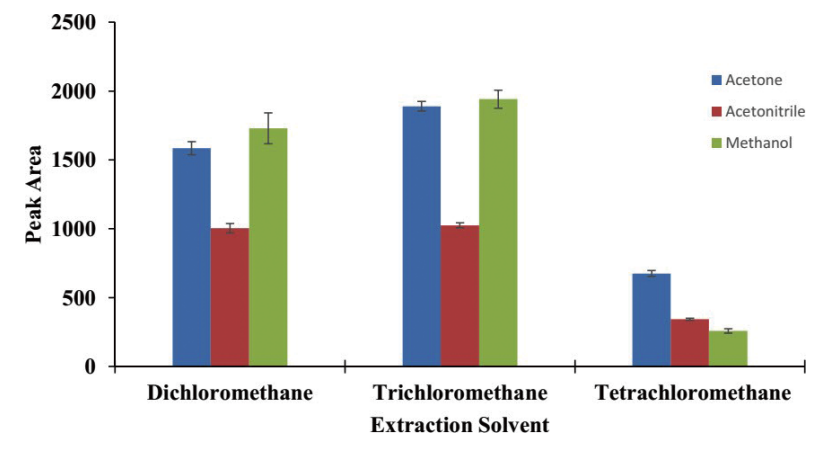

Fig. 1 Effect of the extraction and disperser solvents type on the extraction efficiency of DLLME (propoxur concentration, $1 \mathrm{mg} \mathrm{L}^{-1}$ ).

\section{Procedure}

Dispersive liquid-liquid microextraction: For the preconcentration process, a $4 \mathrm{~mL}$ aqueous solution of propoxur was placed in a $10 \mathrm{~mL}$-conic bottom test tube. Volumes of $78 \mu \mathrm{L}$ of the extraction solvent (trichloromethane) and $1.2 \mathrm{~mL}$ of the disperser solvent (methanol) were firstly mixed, and then injected into the sample solution, rapidly, to appear a cloudy mixture. After centrifugation for $1 \mathrm{~min}$ at $1010 \mathrm{~g}$, the extraction solvent, enriched with the analyte was separated from the aqueous solution. Afterward, a $5-\mu \mathrm{L}$ sediment phase was injected into the sample introduction system for determining the analyte.

To evaluate the DLLME method for the preconcentration of propoxur in a real sample, some samples were used including agricultural wastewater, underground water (obtained from Vandadeh village, Isfahan-Iran) and wastewater of aviculture. Except for wastewater of aviculture, no propoxur was detected in studies of real samples. The samples were spiked with standard solutions of propoxur, for calculating the relative recovery of the method.

\section{Results and Discussion}

Selection of disperser and extraction solvents

Before using the Response Surface Method (RSM), the types of disperser and extraction solvents must be indicated. In this work, the DLLME method based on the extraction solvents with a higher density than water was used. Initially, to obtain comparable results, the ratio of the disperser and extraction solvents was examined for different solvents for reaching out to the same volume of the sediment phase. In this regard, different disperser solvents included acetone, acetonitrile, and methanol; and three extraction solvents of trichloromethane, dichloromethane, and tetrachloromethane were selected for the DLLME method. The volumes of the disperser and extraction solvents needed to obtain a $10-\mu \mathrm{L}$ sediment phase and shown in Table S2 (in Supporting Information). The obtained results are shown in Fig. 1, showing that maximum extraction was achieved for the pair of methanol and trichloromethane.

\section{Optimization of parameters using RSM}

For optimizing the experimental parameters in the DLLME process, the RSM based on Central Composite Design (CCD) was used. To that end, the type and volume of the extraction and disperser solvents, $\mathrm{pH}$, and time of centrifuging were studied and optimized. Firstly to screen the main variables affecting the extraction procedures, a Fractional Factorial 
Table 1 Design matrix and the responses for a fractional factorial $\left(2^{4-1}\right)$ design (variables are coded)

\begin{tabular}{crrrrr}
\hline Run No. & $\mathrm{A}^{\mathrm{a}}$ & $\mathrm{B}^{\mathrm{b}}$ & $\mathrm{C}^{\mathrm{c}}$ & $\mathrm{D}^{\mathrm{d}}$ & Response \\
\hline 1 & 85 & 0.6 & 3 & 1 & 2702 \\
2 & 120 & 1.2 & 3 & 1 & 2676 \\
3 & 120 & 0.6 & 8 & 1 & 2542 \\
4 & 120 & 0.6 & 3 & 4 & 2193 \\
5 & 85 & 1.2 & 3 & 4 & 3443 \\
6 & 85 & 0.6 & 8 & 4 & 3023 \\
7 & 120 & 1.2 & 8 & 4 & 2442 \\
8 & 85 & 1.2 & 8 & 2 & 3406 \\
\hline
\end{tabular}

a. Volume of extraction solvent $(\mu \mathrm{L})$.

b. Volume of disperser solvent $(\mathrm{mL})$.

c. $\mathrm{pH}$ value.

d. Centrifugation time ( $\mathrm{min})$.

Table 2 Analysis of variance (ANOVA) for fractional factorial design

\begin{tabular}{lccccc}
\hline \multicolumn{1}{c}{ Source } & $\begin{array}{c}\text { Sum of } \\
\text { squares }\end{array}$ & $\mathrm{DF}^{\mathrm{a}}$ & $\begin{array}{c}\text { Mean } \\
\text { square }\end{array}$ & $F$-value & $P$-value \\
\hline Model & $1.612 \times 10^{6}$ & 3 & $5.373 \times 10^{5}$ & 20.22 & 0.0070 \\
$A$-Extractor & $1.097 \times 10^{6}$ & 1 & $1.097 \times 10^{6}$ & 41.30 & 0.0030 \\
$B$-Disperser & $3.634 \times 10^{5}$ & 1 & $3.634 \times 10^{5}$ & 13.67 & 0.0209 \\
$A B$ & $1.510 \times 10^{5}$ & 1 & $1.510 \times 10^{5}$ & 5.68 & 0.0757 \\
Residual & $1.063 \times 10^{5}$ & 4 & 26573.62 & & \\
Cor. total $^{\mathrm{d}}$ & $1.718 \times 10^{6}$ & 7 & & & \\
\hline
\end{tabular}

a. Degrees of freedom.

b. Test for comparing model variance with residual (error) variance.

c. Probability of seeing the observed " $F$-value" if the null hypothesis is true.

d. Totals of all information corrected for the mean.

Design (FFD) was carried out. The optimum experimental conditions were obtained by using a trial version of DesignExpert 7.1.3 (Stat-Ease Inc., Minneapolis, USA) software.

\section{Fractional factorial design}

For optimization of the experiment parameters, it is necessary to determine the most important factors that affect the result. This reduces the number of experiments in a multivariable system. After screening experiments, the relationship between the effective factors and the final response were explored for obtaining the optimized experimental parameters. ${ }^{31,32}$ In this regard, the peak area in the ion mobility spectrum was calculated and considered to be the response of the instrument. The main factors examined are presented in Table S3, in Supporting Information. It is notable that the degradation of propoxur may occur in an alkaline condition; $; 3,34$ thus, a $\mathrm{pH}$ range of $3-8$ was selected for studying this parameter. According to the number of variables, eight experiments were designed for FFD, which are listed in Table 1. The ANOVA method was used to examine the precision and accuracy of the design. The results are presented in Table 2. According to the results, the significance of the model can be concluded from the F-value of 20.22, with only a $0.70 \%$ chance of noise generation. General, $p$-values $<0.05$ indicate that the model terms are significant, and the terms with $p$-values of more than 0.1000 are not significant. Thus, based on the results, only the terms of extraction solvent (A) and disperser solvent (B) have a significant effect on the experiment response. Therefore, these parameters should be used in CCD optimization. Other parameters, including the $\mathrm{pH}$ and the time of centrifugation showed a $p$-value of higher than
Table 3 Analysis of variance (ANOVA) for central composite design

\begin{tabular}{lcccrc}
\hline \multicolumn{1}{c}{ Source } & $\begin{array}{c}\text { Sum of } \\
\text { squares }\end{array}$ & Df $^{\mathrm{a}}$ & $\begin{array}{c}\text { Mean } \\
\text { square }\end{array}$ & $F$-value & $P$-value \\
\hline Model & $2.159 \times 10^{6}$ & 5 & $4.318 \times 10^{5}$ & 14.87 & 0.0013 \\
$A$-Extractor & $1.306 \times 10^{6}$ & 1 & $1.306 \times 10^{6}$ & 44.96 & 0.0003 \\
$B$-Disperser & $1.676 \times 10^{5}$ & 1 & $1.676 \times 10^{5}$ & 5.77 & 0.0473 \\
$A B$ & $1.624 \times 10^{5}$ & 1 & $1.624 \times 10^{5}$ & 5.59 & 0.0500 \\
$A^{2}$ & $4.882 \times 10^{5}$ & 1 & $4.882 \times 10^{5}$ & 16.81 & 0.0046 \\
$B^{2}$ & 63602.93 & 1 & 63602.93 & 2.19 & 0.1825 \\
Residual & $2.033 \times 10^{5}$ & 7 & 29047.35 & & \\
Lack of Fit & $1.684 \times 10^{5}$ & 3 & 56148.75 & 6.44 & 0.0519 \\
Pure error & 34885.20 & 4 & 8721.30 & & \\
Cor. total & $2.363 \times 10^{6}$ & 12 & & & \\
\hline
\end{tabular}

a. Degrees of freedom.

b. Test for comparing model variance with residual (error) variance.

c. Probability of seeing the observed " $F$-value" if the null hypothesis is true.

d. Totals of all information corrected for the mean.

0.05 ; thus, their effect on the extraction can be disregarded. The optimum $\mathrm{pH}$ and centrifugation duration were considered to be 7 and $1 \mathrm{~min}$, respectively.

\section{Central composites design}

After screening and determining the effective factors, the CCD method was used to determine the exact values for the optimum conditions of the DLLME. Table S4 (in Supporting Information) gives the effective factors and their symbols and levels in the CCD method. The designed matrix and the corresponding responses are also presented in Table S5 (in Supporting Information). Moreover, the results of the ANOVA obtained for CCD are gives in Table 3. According to these results, the significance of the model is concluded from the $F$-value (14.87). This indicates that there is only a $0.13 \%$ chance for obtaining the "Model $F$-Value" due to noise. According to the $P$ value, $A, B, A^{2}$, and $B^{2}$ are significant terms of the model. The model equation is shown in Eq. (1), and Fig. 2 shows a three-dimensional and counter plot of the CCD model:

$$
\begin{aligned}
& y=2473.80- 406.09 \times A+148.94 \times B- \\
& 201.5 A B+268.00 \times A^{2}+104.03 \times B^{2} .
\end{aligned}
$$

Considering the pure error and the "Lack of Fit (LOF) $F$-value" of 0.04 , the model is not significant. The model quality was evaluated using the coefficient of determination $\left(R^{2}\right.$, adjusted- $R^{2}$, and adequate precision). $R^{2}$ was obtained to be 0.9139 , indicating the accuracy of the model in the prediction of the measured responses. The value of adjusted- $R^{2}$ was equal to 0.8525 , calculated from the significant variables of the model. The signal-to-noise ratio is characterized by the adequate precision and used to compare the predicted values relative to the average error. In this work, the signal-to-noise ratio was obtained to be 10.4950, indicating adequate model discrimination.

\section{Instrumental parameters affecting the analyte signal}

Before analyzing propoxur by an ion mobility spectrometer with the ultrasonic nebulizer, the effects of the IMS cell temperature and the carrier gas flow rate on the signal intensity were investigated.

\section{Cell temperature}

As mentioned in the Introduction section, propoxur is known 

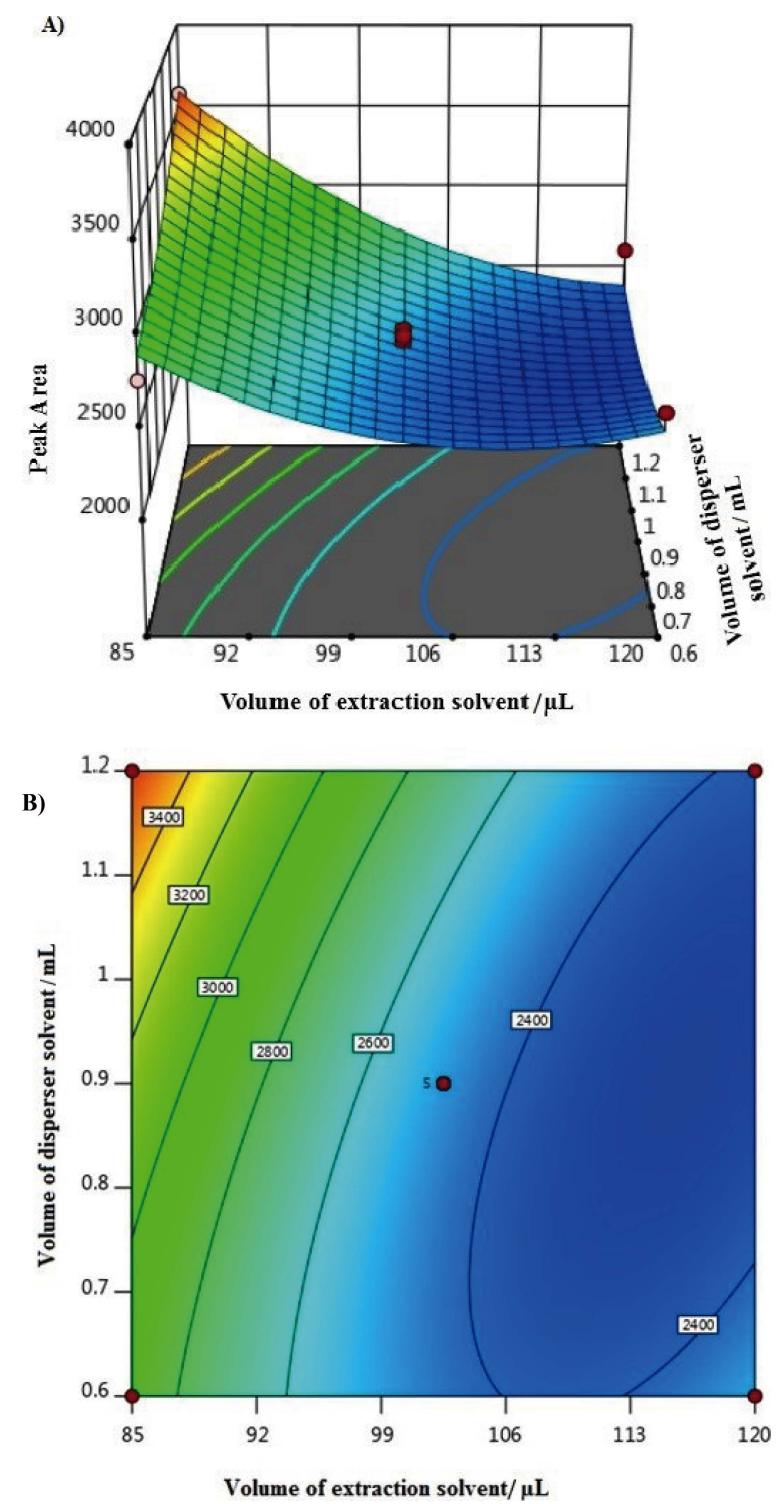

Fig. 2 Three-dimensional (3D) plot (A) and contour plots (B) of the instrument responses for extracted propoxur related to the disperser and the extraction solvents volume.

to be a thermally unstable compound, so the temperature of the IMS cell can affect the analyte signal, significantly. For investigating this parameter, the standard solution of propoxur in methanol $\left(10 \mathrm{mg} \mathrm{L}^{-1}\right)$ was injected into the ultrasonic nebulizer system. The signal (area of the originated analyte peak) was calculated and considered to be the IMS response. As shown in Fig. 3, with increasing the IMS cell temperature, the analyte signal firstly increased up to $140^{\circ} \mathrm{C}$, perhaps due to raising the ionization efficiency. The response was then decreased at higher temperatures because of thermal degradation of the propoxur inside the reaction region.

\section{Carrier gas flow rate}

The produced droplets of the sample were entered into the ionization source by passing the carrier gas (nitrogen) through the ultrasonic nebulizer chamber. The flow rate of this carrier gas should be optimized to achieve the maximum response. To that end, $5 \mu \mathrm{L}$ of a propoxur solution in methanol $\left(10 \mathrm{mg} \mathrm{L}^{-1}\right)$ was injected, and the corresponding response was explored, by varying the carrier gas flow rate. Based on the results depicted

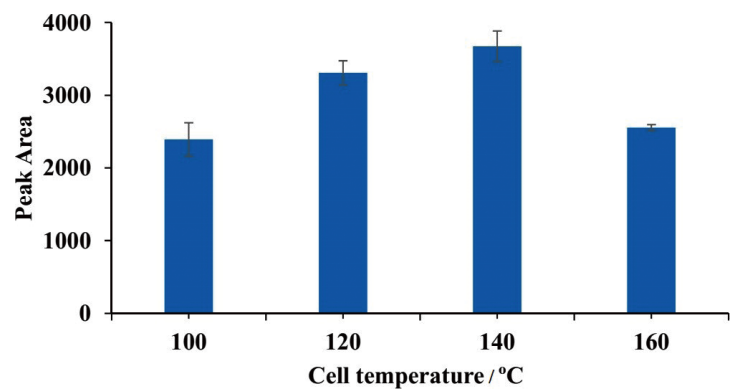

Fig. 3 Effect of the IMS cell temperature on the propoxur signal by using the ultrasonic nebulizer injection port (propoxur concentration, $10 \mathrm{mg} \mathrm{L}^{-1}$ ).

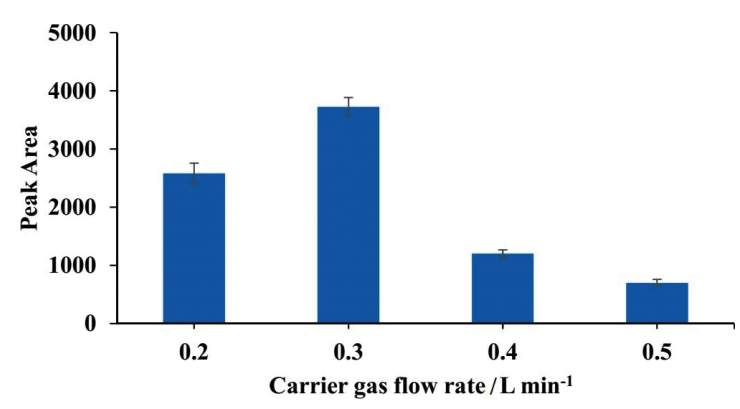

Fig. 4 Effect of carrier gas flow rate on the propoxur signal of IMS (propoxur concentration, $10 \mathrm{mg} \mathrm{L}^{-1}$ ).

in Fig. 4, the maximum IMS response was obtained at a carrier gas flow rate of $0.3 \mathrm{~L} \mathrm{~min}^{-1}$. In fact, flow rates lower than $0.3 \mathrm{~L} \mathrm{~min}^{-1}$ cannot carry the sample into the ionization source, sufficiently; otherwise, the nebulization efficiency might be affected by increasing the gas pressure inside the chamber, at very high gas flows. Thus, a flow rate of $0.3 \mathrm{~L} \mathrm{~min}^{-1}$ was selected for the carrier gas in all subsequent experiments.

\section{Validation of the method}

To evaluate the method, propoxur was extracted from different synthesized sample solutions, and the analyte was determined by IMS. Under the optimum conditions of the method, some figures of merit, including the limits of quantification (LOQ) and detection (LOD), the linear dynamic range (LDR), and the relative standard deviation ( $\mathrm{RSD} \%)$, were calculated for propoxur. The calibration plot of the analyte was provided and the results showed a linear range of from 2.5 to $80 \mu \mathrm{g} \mathrm{L}^{-1}$ with determination coefficients of 0.9977 . The values of LOQ $(S / N=10)$ and $\operatorname{LOD}(S / N=3)$ were calculated to be 5.0 and $2.1 \mu \mathrm{g} \mathrm{L}^{-1}$, respectively. The RDS values were calculated $9 \%$ and $7 \%$ for standard solutions of propoxur, 10 and $60 \mu \mathrm{g} \mathrm{L}^{-1}$, respectively. The enrichment factor of 48 was calculated by the analysis of propoxur in a $40 \mu \mathrm{g} \mathrm{mL}^{-1}$ solution. This value of the enrichment factor is well comparable with some other methods, such as graphene-based solid-phase extraction $(34.2-51.7),{ }^{35}$ single-drop microextraction (38), ${ }^{36}$ micro-solid-phase extraction $(50),{ }^{37}$ which have been used for propoxur extraction previously.

\section{Analysis of field sample}

To further investigate the capability of the DLLME-US-CDIMS, the applicability of the method was examined for the determination of propoxur in different water samples including agriculture wastewater, wastewater of aviculture, and underground water. The extraction and instrumental analysis 

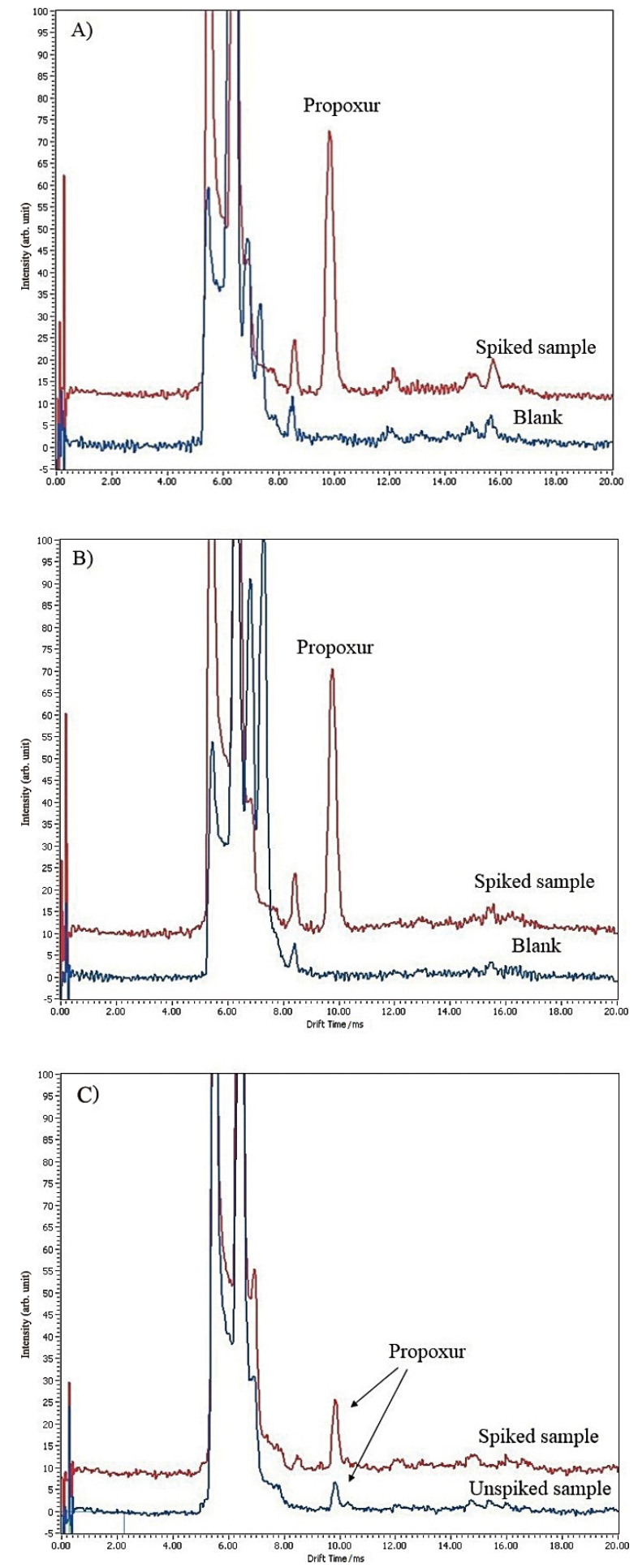

Fig. 5 CD-IMS spectra of propoxur extracted before (blank) and after spiked samples of A) agricultural wastewater, B) underground water, $\mathrm{C}$ ) wastewater of aviculture (the propoxur concentration spiked in A, B real samples are $40 \mu \mathrm{g} \mathrm{L}^{-1}$, and in C real sample is $10 \mu \mathrm{g} \mathrm{L}^{-1}$ ).

were done under the optimum condition obtained as the extraction solvent volume, $78 \mu \mathrm{L}$; disperser solvent volume, $1.2 \mathrm{~mL}$; centrifugation time, one minute, and the $\mathrm{pH}$ value of 7 . Figure 5 shows the ion mobility spectra obtained after injecting the samples extracted from different water solutions compared with their corresponding backgrounds. According to these results, the propoxur peak was not detected in agriculture
Table 4 Analysis of propoxur in real samples by DLLME-USCD-IMS

\begin{tabular}{lccc}
\hline \multicolumn{1}{c}{ Sample } & Added $^{\mathrm{a}}$ & Found $^{\mathrm{a}}$ & $\begin{array}{c}\text { Relative } \\
\text { recovery, \% }\end{array}$ \\
\hline Agricultural wastewater & - & $\mathrm{ND}^{\mathrm{b}}$ & \\
Underground water & 10 & $10.10(5)^{\mathrm{c}}$ & 101 \\
& - & $\mathrm{ND}$ & \\
Wastewater of aviculture & - & $9.90(3)$ & 99 \\
& 5 & $10.10(9)$ & 96 \\
\hline
\end{tabular}

a. Propoxur concentration $\left(\mu \mathrm{g} \mathrm{L}^{-1}\right)$.

b. Not detected.

c. The value of Relative Standard Deviation (\%).

wastewater and underground water, while a peak with considerable intensity was detected for aviculture wastewater. To overcome the matrix interference, the amount of propoxur in the samples was determined by the multiple standard addition technique. The recovery values were calculated based on Eq. (2) for spiked samples, and the results are presented in Table 4 .

$$
\text { Relative recovery }(\mathrm{RR} \%)=\frac{C_{\text {found }}-C_{\text {real }}}{C_{\text {added }}}
$$

Herein, $C_{\text {found }}, C_{\text {real }}$, and $C_{\text {added }}$ are related to the analyte concentration, obtained after adding a certain amount of analyte to sample, the real analyte concentration in the sample, and the analyte concentration which is spiked to sample, respectively. According to the results, the relative recovery values were in the range of $91-102 \%$, and the calculated RSD values were lower than $9 \%$ for real samples. Consequently, this method can be successfully used for the determination of propoxur in real samples.

\section{Comparison with other methods}

Table 5 shows a comparison of some analytical parameters obtained by DLLME-US-CD-IMS with those reported previously by other techniques, for the determination of propoxur in different samples. As shown in this Table, the proposed method has acceptable and comparable LOD and recovery values with other listed methods. Generally, the method of HPLC is used for the separation and detection of thermally unstable compounds. Unlike HPLC, the IMS instrument has a very short time of analysis $(<1 \mathrm{~min})$ and needs a very low volume of solvents; so, applying the ultrasonic nebulizer as a sample introduction system was suggested to provide the possibility of IMS utilized in the determination of thermally unstable compounds of propoxur. On the other hand, the IMS instrument has a high portability potential, which is helpful in the field analysis of samples.

\section{Conclusions}

In this work, propoxur, as a thermally unstable pesticide, was successfully determined by using CD-IMS assisted with an ultrasonic nebulizer injection port. Preconcentration of an analyte was accomplished based on dispersive liquid-liquid microextraction from different water samples. Using an ultrasonic nebulizer as an injection port provides a method to transfer a liquid sample to the gaseous phase at ambient temperature and avoided the thermal decomposition of the analyte. This feature makes the possibility of the analysis of 
Table 5 Comparison of the DLLME-US-CD-IMS method with other reported method for the extraction and determination of the propoxur

\begin{tabular}{|c|c|c|c|c|c|c|}
\hline Analytical method & Real sample & $\mathrm{LOD}^{\mathrm{a}} / \mu \mathrm{g} \mathrm{L}^{-1}$ & $\mathrm{LDR}^{\mathrm{b}} / \mu \mathrm{g} \mathrm{L}^{-1}$ & $\operatorname{RSD}^{\mathrm{c}}, \%$ & Recovery, $\%$ & Ref. \\
\hline MSPE $^{\mathrm{d}}$-HPLC/UV-vis & Apple & $0.2\left(\mathrm{ng} \mathrm{g}^{-1}\right)$ & $1.0-100.0\left(\mathrm{ng} \mathrm{g}^{-1}\right)$ & 5.7 & $89.3-109.7$ & 38 \\
\hline MSPE-HPLC/UV-vis & Water and zucchini & 0.03 & $0.1-100$ & 4.2 & $86.1-99.4$ & 10 \\
\hline USAEME-HPLC/UV-vis & Beverage & 1 & $10-10^{4}$ & 6.2 & $93-106$ & 39 \\
\hline QuEChERS ${ }^{\mathrm{f}}$-LC-MS/MS & Dates & $0.95\left(\mu \mathrm{g} \mathrm{kg}^{-1}\right)$ & $1-200\left(\mu \mathrm{g} \mathrm{kg}^{-1}\right)$ & 7.7 & $90-115$ & 40 \\
\hline MIPs-IPP/GCh & Pig liver & 18.8 & $18.8-9416.8$ & 8.67 & 101.7 & 41 \\
\hline VSLLME'-MEKCj-MS/MS & Juices & 2.3 & $2.3-250\left(\mu \mathrm{g} \mathrm{kg}^{-1}\right)$ & 15 & $81-104$ & 42 \\
\hline MIPs-IMS ${ }^{k}$ & Tap water, agricultural wastewater & 0.3 & $1-250$ & $5-7$ & $94-102$ & 43 \\
\hline DLLME-US-CD-IMS & $\begin{array}{l}\text { Agricultural wastewater, underground water, } \\
\text { wastewater of aviculture }\end{array}$ & 2.1 & $5-80$ & $6-9$ & $96-101$ & $\begin{array}{l}\text { This } \\
\text { work }\end{array}$ \\
\hline
\end{tabular}

a. Limit of detection. b. linear dynamic range. c. Relative standard deviation. d. Magnetic solid-phase extraction. e. Ultrasound-assisted emulsification-microextraction. f. The quick, easy, cheap, effective, rugged and safe method. g. Molecularly imprinted polymer. h. 2-Isopropoxyphenol glassy carbon electrode. i. Vortex-assisted liquid-liquid microextraction. j. Micellar electrokinetic chromatography. k. Ion mobility spectrometry.

thermally unstable compounds. Based on the satisfactory results as well as the advantages of CD-IMS, such as the high speed of analysis, ease of maintenance and relatively high sensitivity, the DLLME-US-CD-IMS method can be suggested as a proper alternative method for the determination of propoxur comparable to the commonly used methods, such as HPLC or GC/MS.

\section{Supporting Information}

This material is available free of charge on the Web at http:// www.jsac.or.jp/analsci/.

\section{References}

1. T. M. G. Selva, W. R. Araujo, and T. R. L. C. Paixao, in "2017 ISOCS/IEEE International Symposium on Olfaction and Electronic Nose (ISOEN)", 2017, IEEE, 1.

2. M. A. Kamrin, "Pesticide Profiles: Toxicity, Environmental Impact, and Fate", 1997, CRC/Lewis Publishers.

3. WHOPES, "WHO Specification and Evaluations for Public Health Pesticides, Propoxur", 2016, WHO.

4. L. Sun and H. K. Lee, J. Chromatogr. A, 2003, 1014, 153.

5. P. H. Howard, "Handbook of Environmental Fate and Exposure Data for Organic Chemicals", 1991, Vol. 3, Taylor \& Francis, 584.

6. WHOPES, "Pesticide Residues in Food 1996, Evaluations, Part 1 (FAO Plant Production and Protection Paper)", 1996, Rome, Italy, 337.

7. A. Hemasundaram and N. V. Naidu, Anal. Sci., 2004, 20, 1707.

8. S. K. Handa and A. K. Dikshit, Analyst, 1979, 104, 1185.

9. S. H. Yuen, Analyst, 1965, 90, 569.

10. M. Li, C. Jiao, X. Yang, C. Wang, Q. Wu, and Z. Wang, Anal. Methods, 2017, 9, 593.

11. Y. Wang, R. Ma, R. Xiao, Q. Wu, C. Wang, and Z. Wang, J. Sep. Sci., 2017, 40, 2451.

12. Y. Fang, W. Tian, F. Pei, P. Li, X. Shao, Y. Fan, and Q. Hu, Food Chem., 2017, 229, 347.

13. J. A. Coburn, B. D. Ripley, and A. S. Chau, J. Assoc. Off. Anal. Chem., 1976, 59, 188.

14. C. W. Stanley and J. S. Thorton, J. Agric. Food Chem., 1972, 20, 1269.

15. J. Zrostlıková, J. Hajšlová, M. Godula, and K. Maštovská, J. Chromatogr. A, 2001, 937, 73.

16. Y. Y. Wigfield, R. Grant, and N. Snider, J. Chromatogr. A, 1993, 657, 219.

17. K. Maštovská, S. J. Lehotay, and J. Hajšlová, J. Chromatogr.
A, 2001, 926, 291.

18. X. Song and H. M. McNair, J. Chromatogr. Sci., 2002, 40, 321.

19. R. Carabias-Martínez, C. García-Hermida, E. RodríguezGonzalo, and L. Ruano-Miguel, J. Sep. Sci., 2005, 28, 2130.

20. M. J. Cohen and F. W. Karasek, J. Chromatogr. Sci., 1970, 8, 330 .

21. J. W. Leonhardt, J. Radioanal. Nucl. Chem., 2003, 257, 133.

22. H. Borsdorf, H. Schelhorn, J. Flachowsky, H.-R. Döring, and J. Stach, Anal. Chim. Acta, 2000, 403, 235.

23. H. M. Dion, L. K. Ackerman, and H. H. Hill, Talanta, 2002, 57, 1161.

24. M. T. Jafari, F. Torki, and M. Saraji, Anal. Sci., 2012, 28.

25. G. A. Eiceman, Z. Karpas, and Herbert Hill Jr, "Ion Mobility Spectrometry", 3rd ed., 2013, CRC Press, Boca Raton.

26. M. T. Jafari, B. Rezaei, and H. Bahrami, Anal. Sci., 2018, 34, 297.

27. A. Sorribes-Soriano, M. de la Guardia, F. A. EsteveTurrillas, and S. Armenta, Anal. Chim. Acta, 2018, 1026, 37.

28. M. T. Jafari and S. Ramazani, Anal. Chim. Acta, 2018, $1038,79$.

29. T. Khayamian, M. Tabrizchi, and M. Jafari, Talanta, 2006 , 69, 795.

30. M. T. Jafari and F. Riahi, J. Chromatogr. A, 2014, 1343, 63.

31. H. Sereshti, V. Khojeh, and S. Samadi, Talanta, 2011, 83, 885.

32. L. Mousavi, Z. Tamiji, and M. R. Khoshayand, Talanta, 2018, 190, 335.

33. H. Chen, R. Chen, and S. Li, J. Chromatogr. A, 2010, 1217, 1244.

34. A. M. Carro, S. Fernández, I. Racamonde, D. GarcíaRodríguez, P. González, and R. A. Lorenzo, J. Chromatogr. A, 2012, 1253, 134.

35. Z. Shi, J. Hu, Q. Li, S. Zhang, Y. Liang, and H. Zhang, J. Chromatogr. A, 2014, 1355, 219.

36. M. Saraji and N. Esteki, Anal. Bioanal. Chem., 2008, 391, 1091.

37. J. Vichapong, R. Burakham, S. Srijaranai, and K. Grudpan, J. Sep. Sci., 2011, 34, 1574.

38. X. Liu, C. Wang, Q. Wu, and Z. Wang, Microchim. Acta, 2016, 183, 415.

39. J. Wu, B. Xiang, and J. Xia, Microchim. Acta, 2009, 166, 157.

40. O. I. Abdallah, S. S. Alamer, and A. M. Alrasheed, Biomed. Chromatogr., 2018, 32, 1.

41. B. Qader, M. Baron, I. Hussain, and J. Gonzalez-Rodriguez, J. Electroanal. Chem., 2018, 821, 16.

42. D. Moreno-González, J. F. Huertas-Pérez, A. M. GarcíaCampaña, and L. Gámiz-Gracia, Talanta, 2015, 139, 174.

43. T. Zargar, M. T. Jafari, and T. Khayamian, Microchim. Acta, 2019, 186, 396. 